\title{
A nojenta prole da rainha Ginga, em parte aos homens semelhante: Bocage e a representação de negros e afro-descendentes no Neoclassicismo português
}

\author{
Ginga Queen's Disgusting Offspring, Only Partly Similar \\ to Humans: Bocage's Representation of Black People \\ and African Descendants on Portuguese Neoclassicism
}

Fernando Morato*

RESUMO

O discurso assumido por alguns poemas de Bocage faz, no final do século XVIII, uma representação bastante marcada de africanos, o que permite indagar qual o sentido que essa representação pode assumir nos contextos literário e social em que se inseria. Com algumas diferenças, tanto os ataques satíricos ao poeta brasileiro Domingos Caldas Barbosa quanto os personagens criados para os poemas pornográficos constroem uma mesma tópica: redução do sujeito a seu corpo e apagamento dos traços de humanidade. O que se testemunha é o estabelecimento de um lugar decoroso para os africanos e afrodescendentes que estão gradativamente ocupando lugares de destaque na sociedade portuguesa.

Palavras-chave: Bocage; africanos; racismo; pornografia.

\section{ABSTRACT}

Some poems written by Bocage make, in the end of the 18th century, a peculiar representation of African people, which leads to the question of the meaning of such a representation in its literary and social context. Both the satiric poems against Domingos Caldas Barbosa, and pornographic poems create characters based on the same topic: the subject is reduced to his body and all of them have all traces of humanity erased. We witness the stablishing of a decorous place for Africans and Afro-descendants who are gradually occupying new spaces on the Portuguese society.

Keywords: Bocage; Africans; racism; pornography.

* Phd Candidate do programa de Estudos do Mundo Lusófono da Ohio State University. 
Morato, F.

A nojenta

prole da rainha

Ginga, em parte

aos homens

semelhante:

Bocage e a

representação

de negros e

afro-descendentes

no Neoclassicismo

português
Revista Letras, Curitiba, UfPR, n. 97, pp. 90-105, jan./jun. 2018. ISSN 2236-0999 (versão eletrônica)
A representação de africanos e/ou afrodescendentes na literatura de língua portuguesa apresenta uma particularidade: sofre uma repentina suspensão no século XVIII. Gil Vicente representa uma grande quantidade deles na primeira metade do século XVI, em obras como Floresta de Enganos, Nau de Amores, Pranto de Maria Parda, e Frágua de Amor, ainda que na chave satírica, evidenciando a importância desses tipos humanos na paisagem social portuguesa, fazendo também um importante registro da "língua de preto" que as caracterizava. Essa representação, entretanto, sofre um decréscimo no século XVII, feita a ressalva importante de Gregório de Matos na Bahia seiscentista ${ }^{1}$, para reaparecer com vitalidade no século XIX, a reboque das discussões científicas. Entretanto, a presença material dessas figuras humanas em Portugal não havia desaparecido, como bem revelam os comentários do inglês William Beckford quando de sua estada na corte de Dona Maria I, em fins do século XVIII:

Saboreavamos pacificamente o cha, quando fomos despertados por uma grande algazarra na rua, e correndo a varanda demos com um grosseiro magote de velhas bruxas, rapazes e mendigos andrajosos, trazendo a sua frente meia duzia de tambores, e

1 Entretanto, como a poesia atribuída a Gregório de Matos centra seu universo de referências mais no Brasil, a presença de africanos se justificaria por outros motivos. 
outros tantos pretos de vestes encarnadas, tocando trombetas com uma vehemencia insolita, e apontando-as directamente para a minha casa! (...) Esta prestes a chegar a Rainha com as suas damas de honor, os secretarios d'estado, os anoes, as pretas e os cavallos brancos... (BECKFORD, 1901, p. 37 e 106) [sic].

O relato de Beckford evidencia claramente a presença dos africanos nos dois extremos da sociedade, tanto entre os "mendigos andrajosos" quanto entre as "damas de honor" da Rainha. Apesar desse fato, a literatura do período parece ignorar a existência dessas figuras. Por isso, neste trabalho procuro rastrear a representação de africanos e afrodescendentes na poesia de Manuel Maria Barbosa du Bocage, nomeadamente nos poemas satíricos e pornográficos, que parecem constituir, um pouco de acordo com a tradição estabelecida, um pouco devido à lógica interna que cria, o "lugar verossímil" para essas personagens. O objetivo deste trabalho, então, é flagrar a dinâmica de representação interna ao universo poético do século XVIII. Para isto, eu vou voluntariamente preferir os debates contemporâneos aos textos àqueles que se constituíram a posteriori. A hipótese que quero demonstrar é a de que os textos poéticos analisados criam uma tópica para o tratamento literário de pessoas negras, qual seja a do rebaixamento desses sujeitos à condição animal. A partir dessa prática, creio que se estabelecem as imagens e tópicas que estarão à disposição dos discursos racistas que se formarão ao longo do século XIX. É, portanto, na representação literária de fins do XVIII, especificamente em textos hoje considerados pornográficos, que se configuram as maneiras de conceber e descrever indivíduos de descendência africana.

É possível afirmar que não há um total desaparecimento dos africanos e afrodescendentes do universo imaginário dos portugueses do século XVIII, mas sim um desvio no olhar, uma vez que encontramos discussões alentadas sobre o lugar, o papel do africano e sua situação em obras como O etíope resgatado, de Manuel Ribeiro Santos (1758), na Nova e Curiosa Relação de um Abuso Emendado (1764) ou na Memória a respeito dos Escravos (1793). O que ocorre é que o tema, nessas obras, é claramente discutido do ponto de vista intelectual, jurídico, filosófico e, sobretudo, econômico. Persiste, então, a tendência de que, uma vez que não estejam associados exclusivamente ao universo do trabalho, não há lugar simbólico para os africanos no universo de referências neoclássico da literatura, já que esta se volta para outros espaços considerados positivos pela tradição letrada. Isso é um ponto importante, uma vez que as questões das regras e do decoro eram dados fundamentais da discussão literária setecentista.

A questão é que, como Beckford havia registrado de maneira eloquente, muitas vezes os espaços mais aristocráticos estavam ocupados por essas figuras. Elas faziam parte integral da sociedade portuguesa, ainda que o esforço de representação fosse o de desviar o olhar delas para outro lado. O problema poderia, então, ser recolocado de maneira mais interessante se pensarmos em termos mais adequados aos das convenções literárias do Neoclassicismo: 1) quais os lugares verossímeis de representação do negro, aqueles em que 
Morato, F.

A nojenta

prole da rainha

Ginga, em parte

aos homens

semelhante:

Bocage e a

representação

de negros e

afro-descendentes

no Neoclassicismo

português

sua presença não pode ser ignorada, e 2) como esses espaços se configuraram. Algumas das obras poéticas de Bocage em que negros e afrodescendentes são representados são os melhores exemplos para entendermos um pouco desse processo, como ele ocorre e quais são as situações verossímeis em que o negro podia ser representado (e de que maneira) na poesia portuguesa do fim do século XVIII.

Ainda que seja possível reconhecer que o Neoclassicismo não foi um movimento monolítico, uma vez que apenas apresentou conflitos de grupos e dissidências as mais variadas $^{2}$, como também experimentou mudanças ao longo do tempo, é importante não perder de mente que sempre existiu nele uma preferência pela homogeneização. A quantidade de traduções, versões e comentários da Arte Poética de Horácio que se imprimiram ao longo da segunda metade do século XVIII e primeira do XIX é uma mostra emblemática de como certos valores e certas práticas são intencionalmente padronizados. O estudo de Ivan Teixeira a respeito do mecenato pombalino (1999) também demonstra bastante bem a generalidade a que autores individuais aspiravam durante os mil-e-setecentos português. Por isso, ainda que a minha análise concentre-se especificamente em um único autor, Bocage, a perspectiva que vou adotar aqui procura flagrar nele o que exista de genérico, e não o que é particular. A prática de escrita que ele adotou, assim como a de seus pares, era consciente da importância da imitação e da manutenção de gêneros e de imagens, como explica lapidarmente Correia Garção na sua Oração Terceira, a respeito da imitação (parte fundamental da primeira operação retórica de escrita, a inventio):

Os poetas devem ser imitados nas fábulas, nas imagens, nos pensamentos, no estilo; mas quem imita deve fazer seu o que imita. Se imito a fábula, devo conservar a acção, ou alma da fábula; mas devo variar de forma os episódios que pareça outra nova e minha. Se imito as pinturas, não devo no meu poema introduzir um Polifemo, mas do painel desse gigante posso tirar as cores para um Adamastor. Se imito o estilo, devo servir-me das palavras dos Antigos, mas achar na linguagem portuguesa termos equivalentes, enérgicos e majestosos, sem torcer as frases nem adoptar barbarismos (GARÇÃO, 135) [sic]

De acordo com esses princípios, ao olhar para o corpus que nos interessa a partir de um corte sincrônico, pretendo reconhecer quais as estratégias e tópicas que se adotam/acrescentam. Há uma consciência explícita de que existem modelos a serem seguidos, mas, ao mesmo tempo, para evitar a "cópia servil", como bem recomenda Garção, esses modelos devem ser ampliados de maneira a criar um novo modelo a ser emulado por outros autores.

Revista Letras, Curitiba, UFPR, n. 97, pp. 90-105, jan./jun. 2018. ISSN 2236-0999 (versão eletrônica)
2 Cf. Braga, 1903.

3 Rodrigues (1992) registra 6 traduções diferentes da Arte Poética entre 1758 e 1827 (a de Cândido Lusitano foi reimpressa duas vezes), às quais se poderiam acrescentar os "Elementos de poética retirados de Aristóteles e Horácio", de Pedro José da Fonseca. 
Destacam-se, portanto, na poesia de Manuel Maria Barbosa du Bocage (1765-1805) dois principais conjuntos de poemas em que afrodescendentes e negros são tratados de maneira explícita: os sonetos em que ele trava polêmica com os sócios da Nova Arcádia e os poemas pornográficos publicados postumamente.

Nos anos 90 do século XVIII, Bocage havia retornado recentemente de sua estadia da Índia (1786-1790) e fazia um esforço para inserir-se nos círculos letrados de Lisboa publicando o seu primeiro poema a ser impresso, uma elegia à morte de D. José Tomás de Meneses em 1790 (Pires, 2016, p. 37). Era por esse momento que se reunia na residência do Conde de Pombeiro, José Luís de Vasconcelos, o grupo de poetas que configurou a chamada Nova Arcádia (em referência àquela fundada em 1756 por Correia Garção, Cândido Lusitano Cruz Silva e Reis Quita, dissolvida em 1776 pelo marquês de Pombal). As reuniões eram lideradas pelo mulato brasileiro Domingos Caldas Barbosa (Lereno Selinuntino, 1740-1800) e delas participavam poetas como Joaquim Severino Ferraz de Campos (Alcino Lisbonense), Belchior Manuel Curvo Semedo (Belmiro Transtagano), Francisco Joaquim Bingre (Francelino Vouguense), Joaquim Franco de Araujo Freire Barbosa (Coridon Neptunino), José Thomaz da Silva Quintanilha (Eurino Nonacriense) e José Agostinho de Macedo (Elmiro Tagidio), então amigo próximo de Bocage. A prática usual era a da recitação de poesias e mútua crítica por parte dos Acadêmicos. Em 1793 foi impresso o Almanak das Musas, em cujos quatro volumes se reuniram poemas escritos pelos sócios.

Bocage foi aceito como convidado no grupo, adotando o nome arcádico que já o caracterizava, Elmano Sadino, e fez inclusive parte da sessão solene em homenagem à Conceição da Virgem que a Arcádia realizou no Passo. É Bingre quem recorda, anos mais tarde, que no caminho dessa sessão, Bocage perguntou a Agostinho de Macedo o que deveria levar para recitar, ao que este teria respondido que não levasse nada porque pretendia improvisar uma oração em prosa; Bocage teria então se entusiasmado a também improvisar versos para o Regente (Gonçalves 170). Assim se deu e os dois amigos foram bastante elogiados, mas este sucesso redundou em algumas discordâncias entre os acadêmicos, porque aparentemente Bocage quis aproveitar o êxito para impor suas concepções poéticas aos outros membros da Arcádia, o que gerou uma reação dos poetas, que já não cultivavam a maior das cordialidades entre si. É deste momento a série de sonetos satíricos que nos interessa, nos quais se destilam ofensas reveladoras de um clima de animosidade, nitidamente movido pelas disputas poéticas, uma vez que os sócios são descritos como autores de "versos maus" e "trovas aleijadas" que causam gargalhadas ao "baixo vulgo", que é uma das figuras mais desprezadas no universo de referências clássicas, como Horácio sintetiza: "Aborreço o profano vulgo e o afasto" (ode 1, livro III). Seguindo a regra de decoro, usar o estilo baixo para a sátira, Bocage chega a lançar mão do calão em alguns sonetos, mas o universo de referências atém-se ao das letras e dos letrados. Houve troca de insultos através de poemas, até que um deles causou desgosto ao Conde de Pombeiro que deu ordem para encerrarem-se as reuniões, o que repercutiu inclusive na ausência de obras de Bocage na publicação do Almanak das Musas. O soneto que desencadeou esses acontecimentos é este: 
Morato, F.

A nojenta

prole da rainha

Ginga, em parte

aos homens

semelhante:

Bocage e a

representação

de negros e

afro-descendentes

no Neoclassicismo

português
Preside o neto da rainha Ginga

À corja vil, aduladora, insana:

Traz sujo moço amostras de chanfana,

Por copos desiguais se esgota a pinga;

Vem pão, manteiga, chá, tudo à catinga;

Masca a farinha a chusma americana;

E o orango-outang a corda à banza abana

Com gestos e visagens de mandinga:

Um bando de comparsas logo acode

Do fofo Conde ao novo Talaveiras;

Improvisa berrando o rouco bode.

Applaudem de contínuo as frioleiras

Belmiro em dithyrambo, o ex-frade em ode;

Eis aqui do Lereno as quartas-feiras. (BOCAGE, 1875, p. 200)

[sic]

Se persistem aqui, como nos poemas anteriores, o registro baixo ("corja vil", o "moço sujo") e a crítica ao estilo ("Applaudem... Belmiro em dithyrambo, o ex-frade em ode"), a nós interessa uma mudança no tipo de insultos que a voz poética utiliza. Ao mencionar Domingos Caldas Barbosa, presidente da associação, o soneto o caracteriza primeiro como "Neto da Rainha Ginga", a legendária rainha angolana que negociou com os portugueses a colaboração no tráfico negreiro no “a corda à banza abana / Com gestos e visagens de mandinga”. Estas são todas ofensas que não dizem respeito, como as anteriores, à falta de qualidades poéticas dos escritos de Caldas, mas sim ao fato de ele ser mulato, filho de um português e provavelmente uma escrava. A questão das origens vem claramente indiciada no poema desde a expressão "neto da rainha Ginga", e se reforça ao fixar boa parte do universo semântico ao redor de elementos americanos (pinga, farinha, catinga) e de traços corporais. É no corpo que se encontram os principais defeitos da personagem da sátira, seja no corpo "herdado" quanto no corpo performado através dos gestos com que toca a guitarra (corda da banza), uma das qualidades mais comentadas pelos espectadores que viram Caldas Barbosa em muitas apresentações na corte.

Note-se também que essa redução da personagem a seu corpo vem acompanhada de outro elemento muito importante, a metáfora que a animaliza: “ourango-outang”. Não apenas há um movimento de rebaixamento das qualidades artísticas quanto das próprias qualidades humanas do Caldas, a personagem é associada não exclusivamente à América, mas também à África, já que é descendente da rainha Ginga. É importante esse trânsito do traço africano para o animal, porque ele é justamente o móvel da imagem que se constrói em outro soneto:

Revista Letras, Curitiba, UFPR, n. 97 , pp. 90-105, jan./jun. 2018. ISSN 2236-0999

(versão eletrônica) 
Lembrou-se no Brazil bruxa insolente

De armar ao pobre mundo extranha peta;

Procura um mono, que infernal careta

Lhe faz de longe, e lhe arreganha o dente:

Pilhando-o por mercê do Averno ardente,

Conserva-lhe as feições na face preta;

Corta-lhe a cauda, veste-o de roupeta,

E os guinchos lhe converte em vez de gente:

Deixa-lhe os calos, deixa-lhe a catinga;

Eis entre os lusos o animal sem rabo

Prole se acclama da rainha Ginga:

Dos versistas se diz modelo, e cabo;

A sua alta sciencia é a mandinga,

O seu benigno Apollo é o Diabo. (BOCAGE, 1875, p. 209) ${ }^{4}$ [sic]

Aqui estão devolta a Rainha Ginga, rima "natural” para "mandinga” e acrescenta-se ao retrato que avizinha o africano do símio uma "cara preta", a "catinga" (cheiro forte, antes generalizado para todas a assembleia da Nova Arcádia) e uma pele grossa, cheia de "calos". A insistência neste tipo de ofensa é significativa, uma vez que aos outros membros da Nova Arcádia é silenciado qualquer tipo de referência a características físicas: eles são poetas enfadonhos, medíocres, inábeis, ou seja, não têm nem corpo nem gestos. Quando suas ações são mencionadas, estão associadas à atividade poética ("Applaudem de contínuo as frioleiras/ Belmiro em dithyrambo, o ex-frade em ode;" - "Vibram tiros ao vate"), enquanto ao Caldas a poesia é quase toda mantida ao abrigo da crítica (a única menção é o hiperbólico sucesso como improvisador, já que é “modelo de trovistas”) para centrar-se o insulto exclusivamente nos elementos corpóreos, tanto físicos quanto gestuais. Isso é ainda mais flagrante porque o próprio Bocage, em outro soneto, reconhece que Caldas é uma pessoa pacata e talentosa, que se manteve ao largo de toda a polêmica:

\author{
A Lereno, que é homem de juizo, \\ Por muitos versos, cheios de belleza, \\ Perdoa, se não gostas de improviso: \\ O egypcio entremez elle despreza; \\ Nos outros, sócio Elmano, é que é preciso, \\ Palhas, dieta, e vergalhada teza. (BOCAGE, 1875, p. 207) [sic]
}

\footnotetext{
4 As informações paratextuais são ambíguas, uma vez que, para este soneto (n. 199), dizem "Ao trovista Caldas, pardo de feições, e grenha crespa e revolta (Metamorphose)", enquanto o anterior (n. 198), que vai ser discutido mais adiante, diz apenas "Ao mesmo", referindo-se ao anterior (n. 197) "Ao Padre Domingos Caldas Barbosa". Como no soneto 198 Apolo diz que nomeou seu bugio "Caldas" e lhe deu "o dom das trovas", o que coincide com a didascália do soneto 199. De qualquer modo, veremos que o universo semântico e imagético mantém-se em todos os textos relacionados a africanos.
} 
Morato, F.

A nojenta

prole da rainha

Ginga, em parte

aos homens

semelhante:

Bocage e a

representação

de negros e

afro-descendentes

no Neoclassicismo

português
Intelectualmente o poeta americano é, portanto, uma figura respeitável; o que não merece respeito é sua condição física. Não seria ocioso reconhecer que, quando Caldas é merecedor de elogio, é tratado por seu pseudônimo arcádico, Lereno, através do qual abstrai-se sua condição física. A animalização retorna num outro soneto, no qual mais uma vez o talento poético é reconhecido:

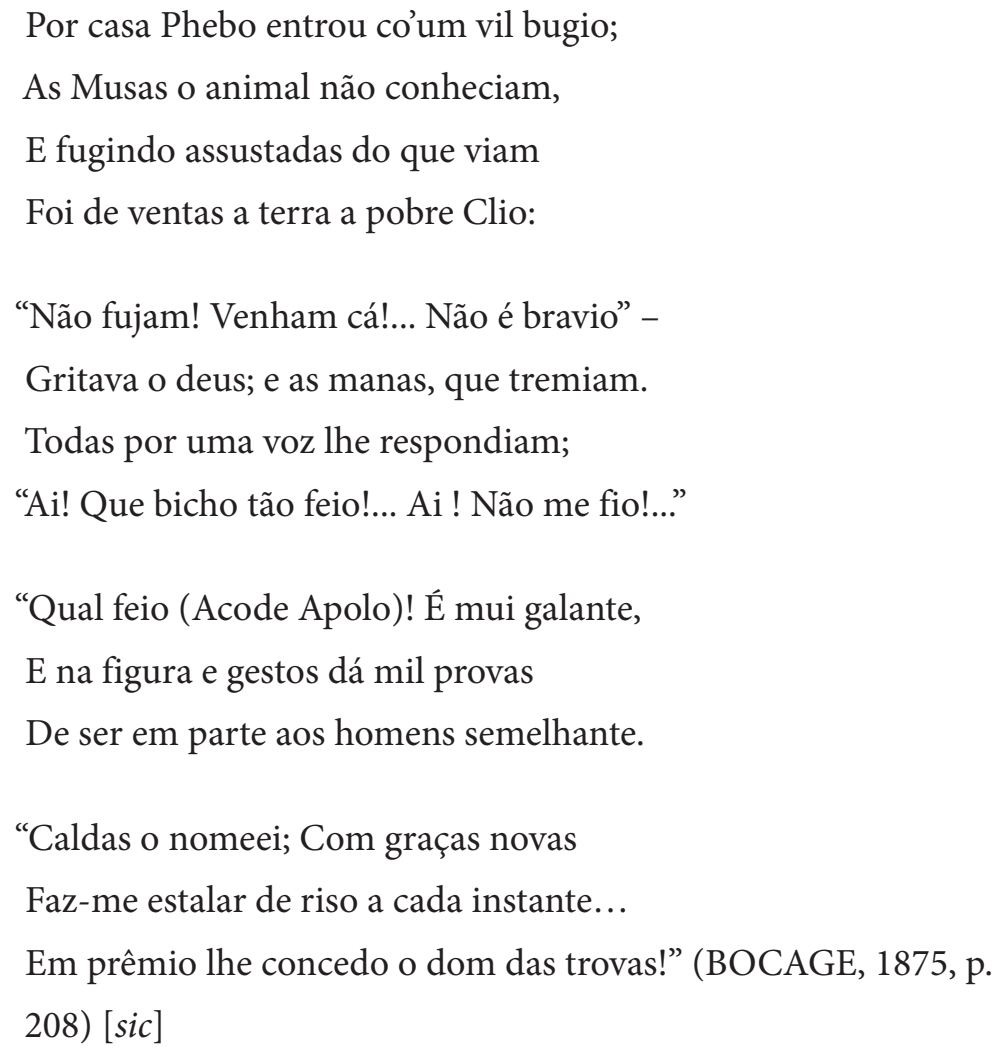

O prêmio do "dom das trovas", ainda que poeticamente menos nobre e possivelmente carregado de ironia, pelo menos desperta o riso de Apolo (não do "baixo vulgo", como acontece com os outros árcades), que em outro dos sonetos exulta apenas com os ataques que o próprio Bocage desfere contra os sócios da Nova Arcádia. A nota que persiste, entretanto, é a da questão física, que aqui avança mais uma vez no sentido da desumanização do Caldas: "na figura e gestos/ Dá mil provas de ser em parte aos homens semelhante" (grifo meu). O foco não está naquilo que nega a diferença em relação aos animais (o talento), mas aquilo que a reforça e precariza, já que é apenas "parte de humanidade". O grande defeito de Caldas não é nem a poesia nem a inteligência, visto que estas são reconhecidas (embora apenas na persona Lereno) mas sim o corpo, ao qual é reduzido. O elemento definidor, porque evidente, é a sua africanidade, que está restringida ao seu corpo.

A este quadro que se vem montando, que poderia quem sabe ser lido numa chave reducionista como revelador apenas dos "preconceitos pessoais" de Bocage, acrescente-se uma circunstância interessante: no depoimento feito por Bingre sobre a passagem de Elmano Sadino pela Nova Arcádia, ele insiste que o soneto "Preside o neto da Rainha Ginga", que causou o encerramento da agremiação, não é de Bocage, mas sim de um dos próprios árcades, Curvo Semedo, que se inseriu no poema (ele era, na Arcádia, Belmiro Transtagano) para "encobrir” a autoria e assim criar maior
Revista Letras, Curitiba, UfPR, n. 97, pp. 90-105, jan./jun. 2018. ISSN 2236-0999 (versão eletrônica) 
animosidade contra o primeiro. A crer em Bingre, reconhecemos que os mesmos insultos e a mesma redução de Caldas exclusivamente a seu corpo são operados tanto pelo inimigo (ainda que reconheça talento) quanto pelo suposto amigo. $\mathrm{O}$ que poderia parecer um preconceito pessoal é, na realidade, algo mais espalhado pela sociedade e pela poesia portuguesa. Como neste momento a questão da criação poética passa necessariamente pelo decorum (a adequação de estilo à matéria), o que estes poemas todos revelam é qual é o tratamento conveniente que se está aceitando para os afrodescendentes quando não é possível desviar o olhar deles. O problema não é o talento, mas o lugar ocupado, como sintetiza de maneira lapidar um outro soneto atribuído a Bocage, já que não foi inserido nas suas obras e sim nas Poesias Eróticas, Burlescas e Satíricas, publicadas postumamente:

Nojenta prole da rainha Ginga,

Sabujo ladrador, cara de nico,

Loquaz saguim, burlesco Teodorico,

Osga torrada, estúpido resinga,

Eu não te acuso de poeta pinga!

Tens lido o Mestre Inácio e o bom Supico;

De oca ideias tens o caco rico...

Mas teus versos tresandão a catinga.

Se a tua musa nos outeiros campa,

Se ao Miranda fizeste ode demente,

E o mais que ao mundo estólido se encampa,

É porque sendo, ó Caldas, tão somente

Um cafre, um gozo, um néscio, um parvo, um trampa

Queres meter nariz em cú de gente. (Bocage, 1860, p. 128) [sic]

Um elemento fundamental é acrescentado ao retrato já sobejamente conhecido que desumaniza o Caldas ("prole da rainha Ginga", "saguim”, "osga torrada”), que é o fato de "quere[r] meter o nariz em cú de gente", numa alusão ao trânsito que ele tinha em vários círculos nobres do Portugal de fins do século XVIII. O que incomoda é a presença, a visibilidade desse corpo no "lugar errado", que evidencia uma realidade que quer ser escamoteada o máximo possível. A maneira de punir esse corpo importuno é privar-lhe dos atributos de humanidade: ele é sabujo ladrador, loquaz saguim, bugio, ourango-outang, mono. Esse é um ponto que fica muito claro num outro soneto insultuoso de Bocage, agora dirigido ao mulato brasileiro Joaquim Manoel, "grande tocador de viola e improvisador de modinhas", o tom se altera:

Vivem por hi alguns de varias tretas,

Com um eu esbravejo, em outros mango;

Que ópio dás ao machete orang-outango.

$\mathrm{Tu}$, gloria das carrancas semi-pretas! 
Morato, F.

A nojenta

prole da rainha

Ginga, em parte

aos homens

semelhante:

Bocage e a

representação

de negros e

afro-descendentes

no Neoclassicismo

português
Quando acompanhas da infernaes caretas

Insípido londum, ou vil fandango,

Não posso tal soffrer: eu ardo, eu zango,

Que no auge do assombro te intromettas:

Crespo Arion, Orphêo de carapinha!

Já de sobejo tens fartado a gana

No seio da formosa pátria minha:

Com faro de chulice americana

Para o cálido sul cortando a linha

Vae cevar-te no coco, e na banana. (Bocage, 1875, p. 176) [sic]

O grande crime de Joaquim Manoel é "farta[r] a gana/ No seio da formosa pátria minha", motivo pelo qual deve ir para o "cálido sul" cevar-se "no coco e na banana". São diversas peças que vão se montando no sentido de explicitar o problema ligado a essas figuras: sua presença física no "espaço errado". A maneira de incorporá-las discursivamente, já que aqui não é possível simplesmente desviar o olhar, é reduzi-las à animalidade, destituindo-as de humanidade.

Muito interessante é o fato de que esse mesmo movimento pode ser percebido no outro conjunto de poemas bocageanos que sistematicamente representam africanos e afrodescendentes, os poemas pornográficos. Reunidos postumamente (1860) por Inocêncio da Silva nas Poesias Eróticas, Burlescas e Satíricas, essas obras primeiro circularam em manuscritos, na maior parte dasvezes anônimas, e aos poucos convergiram de maneira genérica para terem sua autoria atribuída ao poeta de Setúbal, provavelmente o mais talentoso cultor desse gênero em Portugal e a essa altura já uma figura de renome no anedotário popular. Da mesma maneira que acontece com o soneto "Preside o neto da rainha Ginga", o fato de esses poemas terem tal fluidez de atribuição é indicativo não apenas da prática do tempo, caracterizado pela observância das mesmas regras por quase todos os poetas, independentemente de suas particularidades pessoais, e serve também como indicativo de valores sociais mais espalhados.

Da mesma forma que é necessário ser cauteloso com a "personalização" de poemas do século XVIII, é importante, quando nos aproximamos de obras deste tipo, que tematizam o erotismo, tomar cuidado com uma leitura anacrônica que procuraria reconhecer nelas a manifestação exclusiva de um espírito libertário que na verdade tem mais de romântico que neoclássico. Existe uma longa tradição de estudos da poesia de libertinagem e de seus possíveis significados políticos ${ }^{5}$, mas para este meu trabalho prefiro centrar o foco nos aspectos conservadores e não nos inovadores dessa prática. É Alcir Pécora quem chama a atenção para este aspecto: a matéria baixa é uma a mais à disposição do estro de um poeta que se conceba

5 Para esta vertente de análise, recomenda-se a introdução do volume VII das Obras Completas de Bocage, Poesias Eróticas, Burlescas e Satíricas, a cargo de Daniel Pires. Significativamente, a análise através da qual Pires justifica sua leitura volta-se preferencialmente para textos "exclusivamente brancos", como a epístola "Pavorosa ilusão da eternidade" ou as Cartas de Olinda e Alzira.
Revista Letras, Curitiba, UFPR, n. 97, pp. 90-105, jan./jun. 2018. ISSN 2236-0999 (versão eletrônica) 
talentoso e, como qualquer outra matéria, deve ser tratada de maneira conveniente (com decorum). Se aos temas altos correspondem divindades e imagens elevadas, aos temas baixos correspondem deuses e imagens simetricamente opostas:

A simetria dos decoros é rigorosa... Alcança, por exemplo, a pintura do caráter da amada: aquilo que no gênero alto é "tirania" ou "esquivança", no baixo é apetite excessivo, incontinência sexual; o que no alto é "ingratidão" ou "mudança", "feminil costume", no baixo é venalidade, prostituição, crime contra natura, enfim, monstruosidade. Perfeições do corpo da amada, na matéria alta, podem esconder (e em geral escondem) "refinado veneno em taça de ouro", na baixa, quando existem, e não são apenas ruínas e deformidades (e em geral o são), guardam marcas explícitas de cobiça e bestialidade. (PÉCORA, p. 224)

Desde este ponto de vista, a poesia baixa (à qual pertencem os gêneros satíricos) reforça o status-quo, uma vez que ocupa um lugar legítimo dentro do universo do verossímil e do aceito. Entretanto, é importante atentar para o fato de que, se esta simetria se apresenta de forma tão clara no exemplo do retrato da amada, não existe um "equivalente superior" e consequentemente positivo para as figuras dos africanos, a não ser que consideremos este como a pura humanidade. A equivalência que podemos reconhecer é, por assim dizer, "lateral": as mesmas imagens usadas nos poemas para insultar Caldas Barbosa estão presentes nos poemas pornográficos "Ribeirada" e "A Mantegui", ainda que eles apresentem um elemento a mais (o erotismo) na construção desse pequeno mosaico em que flagramos as representações poéticas dos negros em Portugal.

"Ribeirada" é provavelmente um dos primeiros exercícios poéticos de Bocage, uma vez que é um dos seus únicos poemas que tem a ação passada em sua cidade natal, Setúbal, onde vive o protagonista. A narrativa é simples: Ribeiro, negro pobre que tem um pênis enorme, não tem seus apetites sexuais satisfeitos; por isso, uma noite, recebe a visita do deus Príapo, que lhe promete uma esposa (ou mais precisamente, "um cono"); na noite das núpcias, celebrada com precariedade, a moça, a princípio se anima com o volume do pênis do marido, mas logo se arrepende, porque ele a machuca quando se inicia a relação; ao verificar que após terminada a cópula sua vagina ficou exagerada e irremediavelmente aberta, vinga-se de Ribeiro traindo-o; ele, por sua vez, aceita as traições sem queixar-se. Encerra-se o poema com uma lição:

Agora vós, fodões_encarniçados,

Que julgais agradar ás moças belas

Por terdes uns marsapos, que estirados

Vão pregar c'os focinhos nas canellas:

Conhecereis aqui desenganados

Que não são taes porrões do gosto d’ellas:

Que lhes não pode, em fim, causar recreio

Aquelle, que passar de palmo e meio. (Bocage, 1860, p. 18) 
Morato, F.

A nojenta

prole da rainha

Ginga, em parte

aos homens

semelhante:

Bocage e a

representação

de negros e

afro-descendentes

no Neoclassicismo

português

Aceitando a ideia de que este seja um dos primeiros poemas de Bocage, anterior a sua viagem para a Índia (e do contato mais cotidiano com não europeus), encontramos um retrato do africano que já revela quase todos os elementos que mais tarde serão usados para atacar a Caldas Barbosa: Ribeiro é chamado "bruto", "cachorro", "monstro escuro", "horrível brutamontes", além de que "encrespava as ventas como os burros" e, na primeira noite com sua esposa, "zurra" de excitação. Mudaram os animais, mas o símile é da mesma natureza. Segundo a perspectiva adotada aqui, o que estamos vendo não é a representação realista ou não de um tipo de corpo e sim a constituição de um universo de referências conveniente para esse tipo de operação ou, em outras palavras, uma tópica. Apesar de todas estas características fazerem muito sentido quando se pensa nas convenções do gênero baixo, é interessante reforçar que elas não se aplicam a personagens de origem europeia nem na própria "Ribeirada" nem em outros poemas pornográficos de Bocage. Ainda que a esposa de Ribeiro (que, por não ter nenhuma indicação de raça, assume-se que seja branca) seja reduzida a uma "cono", ela continua a ser humana em vários sentidos - a "bestialidade" mencionada por Pécora tem, portanto, níveis e decoros diferentes.

Em "A Mantegui", que trata de uma mulher branca incontinente, não há nenhuma caracterização da protagonista como animal (ainda que ela seja dominada pelos mesmos apetites sexuais de Ribeiro) - esta caracterização é, no poema, novamente destinada a um negro. A narração é também bastante simples: Mantegui, uma jovem de formidáveis atributos físicos que desperta lascívia em todos os homens, aproveita de seus dotes para prostituir-se; Amor, para castigar-lhe a cobiça, a faz apaixonar-se por um "sórdido cafre asselvajado" que, a princípio, se entusiasma vendo-se objeto de desejos de uma mulher tão bela, mas logo fica exaurido e foge da casa deixando-a solitária e insatisfeita. Além das mesmas caracterizações que já apareceram na "Ribeirada" (negro como sujo, selvagem, chamado de cachorro), encontramos aqui também nova metáfora para o pênis desproporcional: "levanta a tromba o ríspido elephante". Insiste-se, assim em associar a imagem do negro ao universo selvagem/animal. E se há algo de distintivo no negro, isto restringe-se ao físico (pênis desproporcional). Não passe despercebido o fato de que, na "simetria dos decoros", se o amor de uma heroína é o prêmio elevado para uma personagem virtuosa, o africano aqui consiste no castigo destinado a quem não tem valor.

Nos dois poemas, então, a figura do negro é associada a um pênis exageradamente grande. Mesmo que isto possa parecer à primeira vista algum tipo de valorização, de caracterização com aspecto minimamente positivo, é necessário contextualizar o "mangalho enorme" de Ribeiro no universo de referências criado pela poesia erótica atribuída a Bocage. Essa característica aparece em outro soneto das Poesias eróticas, burlescas e satíricas, que descreve o espanto que o membro causa nas pessoas (ou mais precisamente no eu poético).

Revista Letras,

Esse disforme, e rigido porraz

Do semblante me faz perder a côr;

E assombrado d'espanto, e de terror

Dar mais de cinco passos para traz:

Curitiba, UFPR,

n. 97, pp. 90-105,

jan./jun. 2018.

ISSN 2236-0999

(versão eletrônica) 
A espada do membrudo Ferrabraz
De certo não mettia mais horror:
Esse membro é capaz até de pôr
A amotinada Europa toda em paz:
Creio que nas fodaes recreações
Não te hão de a rija machina sofrer
Os mais corridos, sórdidos cações:
De Vénus não desfructas o prazer:
Que esse monstro, que alojas nos calções,
É porra de mostrar, não de foder. (BOCAGE, 1860, p. 113) [sic]

Aqui o "rígido porraz" não é associado claramente a algum tipo racial, podendo mais verossimilmente pertencer a um branco, já que se relaciona com universo simbólico da conturbada Europa do fim dos setecentos, a que poderia até colocar em paz. Talvez por isso, as imagens se desviem da animalidade e puxem para o cavalheiresco (o gigante Ferrabrás), que faziam parte do imaginário popular. Tudo isso leva a um dado interessante: diferentemente do que acontecia em "Ribeirada" e "A Mantegui", homem bem-dotado não é nem cafre nem seu pênis uma tromba, mas sim uma "rija machina".

A mesma verossimilhança baixa de todos os poemas pornográficos lidos até agora se estabelece, tanto no vocabulário chulo quanto nas imagens prosaicas, todavia, como aqui não há nenhuma referência à cor da pele deste indivíduo, há outro tipo de tópica conveniente à representação do corpo, aqui reduzidos a "coisa" na medida em que são comparados a ferramentas ("machina" e "guindaste", respectivamente). Significativamente, não há nenhuma animalização como aquela às quais Ribeiro e o amante negro de Mantegui são submetidos. Estes eram o "lascivo animal" e o "cafre asselvajado", enquanto aqueles são poupados de outros atributos animais. Isto nos leva a perguntar: o que existe nesses corpos para distinguir a sua representação verossímil?

Se todos continuam sendo exemplos da "rigorosa simetria dos decoros" descrita por Alcir Pécora, eles estão, então, revelando quais as tópicas que o tempo considera adequadas a cada um desses elementos da equação social que é representada na poesia. Seria equivocado imaginar alguma particular afinidade da figura biográfica de Bocage com as visões expressas em seu poema (se quisermos usar um termo anacronicamente explicativo, ele é apenas um veículo para um discurso). Uma vez que não é a "visão pessoal" que preside as escolhas do poeta, essa ausência de pessoalidade (ou, melhor dito, essa obediência às regras do decorum) indica mais um dos lugares simbólicos ocupado pelos africanos e afrodescendentes no pensamento português de fins do século XVIII. O contraste entre essas poesias que tratam de homens sexualmente deformados revela qual é animal, qual é máquina. Há, portanto, uma sub-hierarquia dentro do baixo, assim como havia uma sub-hieraquia nas sátiras destinadas aos membros da Nova Arcádia, um lugar simbólico (decoroso) para os negros e outro para os brancos. 
Morato, F.

A nojenta

prole da rainha

Ginga, em parte

aos homens

semelhante:

Bocage e a

representação

de negros e

afro-descendentes

no Neoclassicismo

português
Revista Letras,

Curitiba, UfPR,

n. 97, pp. 90-105,

jan./jun. 2018.

ISSN 2236-0999

(versão eletrônica)
Como havíamos visto, os africanos eram preferencialmente ignorados. $\mathrm{O}$ problema começava quando eles, como Caldas Barbosa ou Joaquim Manoel, se faziam visíveis no espaço reservado aos brancos. Os poemas pornográficos estão lidando com um problema semelhante: como lidar com essas personagens quando elas começam a ocupar o imaginário. Pior: o que fazer quando, devido à simetria dos decoros, as suas "qualidades animais" representariam uma nítida vantagem?

Quem sabe uma possível resposta para essa mudança esteja no raciocínio do soneto "Esse disforme e rígido porraz": a voz poética condena o homem "bem dotado" a não desfrutar "de Vênus os prazeres”, já que é demasiado grande para as “fodaes recreações". É a mesma lição que o exórdio da "Ribeirada" dava aos "fodões encarniçados": além de estes "porrões” não serem "do gosto delas", a vingança dos estragos por eles causados é a desqualificação viril através da traição. Bocage (e, por antonomásia, o pensamento poético de fins do século XVIII) ao mesmo tempo em que priva aquele que "passar de palmo e meio" do prazer sexual, restringe essa característica de desproporção aos negros, fazendo do que seria uma qualidade um impedimento. $\mathrm{O}$ último verso do soneto é eloquente: tal característica consiste em "porra de mostra, não de foder", reduzindo mais uma vez o seu eventual possuidor a um ser inútil, ainda que curioso, um objeto destituído de humanidade/serventia. Dessa maneira, aquilo que poderia ser uma qualidade, ao ser desqualificada, torna-se simultaneamente atributo preferencial de africano.

A tópica promove, então, essa nova associação negro-sexualidade. Lembremos mais uma vez e sempre que, assim como em todos os poemas neoclássicos, os de Bocage evidenciam menos um ponto de vista individual que uma visão socialmente difundida. Neste sistema fechado de imagens e referências, nem o baixo nem o pornográfico têm sentido remotamente libertário porque na verdade estão, como disse Alcir Pécora, plenamente integrados em uma hierarquia simétrica de decoros. A prática de estabelecer os modelos adequados e preservá-los (ainda que não de maneira servil), exposta mais acima pelas recomendações de Coreia Garção, não se restringe aos gêneros de maior visibilidade social, mas pode ser perfeitamente reconhecida nos gêneros satíricos também. Na poesia elevada, a presença do negro não existe, ao redor dele faz-se um impressionante silêncio, quem sabe fruto de um desvio de olhar. Há momentos, entretanto, em que não é possível fazer esse desvio (Beckford nos dava um exemplo, mas ele escrevia memórias, não poesia), então para esses momentos, reservam-se os gêneros baixos. O interessante é que, mais que a restrição aos gêneros baixos, as imagens, tanto nas sátiras contra o Caldas quanto nas narrativas pornográficas, optem por uma desqualificação a mais, a desumanização. As tópicas estão se rearranjando e fazem a opção por uma representação que enxerga a diferença como uma falta fundamental (mesmo quando ela é, aparentemente, abundância). Enxergar o negro de frente pressupõe um movimento de transformação desse indivíduo em objeto (o que já acontecia, em outro nível, por ele ser escravo ainda nas colônias) mas também de animal. Apolo dizia no soneto: Caldas "na figura e gestos dá mil provas / De ser em parte aos homens semelhante." Essa parte é necessariamente a menor, e vem de um passado ancestral, a Rinha Ginga, tornando-se 
atributo que passa de geração em geração. Essa vai ser a herança simbólica que a cultura do Antigo Regime vai deixar para o século XIX no que diz respeito ao tratamento literário dos africanos e desemboca no racismo.

Mas, para a nossa leitura de sujeitos do século XXI, o importante é notar quais eram esses decoros, quais os lugares verossímeis de certas personagens. Da mesma maneira que na poesia pornográfica, a poesia satírica mostra que há um locus conveniente para representar o africano na cultura portuguesa de fins do século XVIII, um locus que desconsidera qualquer agência intelectual em benefício da agência física e, assim como a pornografia privava esses sujeitos de qualquer possibilidade de gozo, na sátira poética priva-os de reconhecimento performático (as "quartas-feiras de Lereno" são um desastre sobretudo pela presença desse elemento grotesco representado pelo mulato, seu cheiro e seus gestos).

O discurso racista de pretensões científicas do século XIX ainda não está configurado, mas certamente ele deve, no mundo de língua portuguesa, um grande tributo ao imaginário formado pelos autores "ilustrados" do século anterior. No momento de sua eclosão, ele encontrará à disposição todo um sistema de tópicas e imagens que terá larga fortuna. O que estamos vendo em fins do XVIII éa construção de um discurso moral no qual se encontram as possibilidades (ou melhor, falta de possibilidades) de representação do grupo humano que então estava ocupando incomodamente um novo espaço. Se "preside o neto da rainha Ginga" explicita o desconforto causado pela presença desse corpo, é nos poemas pornográficos que se codificam mais claramente os limites desse corpo "outro": "De Vênus não desfrutas os prazeres". O sexo serve, aqui, para domesticar e restringir mais que para libertar, justamente porque se combina com outro discurso disciplinador, o do preconceito. Reduzidos aos seus corpos não-funcionais, justamente porque juridicamente não são mais escravos (pelo menos em Portugal), os africanos estão prontos para terem esses corpos catalogados e constrangidos por outro discurso, o racista. 
Morato, F.

A nojenta

prole da rainha

Ginga, em parte

aos homens

semelhante:

Bocage e a

representação

de negros e

afro-descendentes

no Neoclassicismo

português

\section{Referências}

BECKFORD, William. A corte da Rainha Maria I, Correspondência de W. Beckford. Lisboa: Livraria Editora Tavares Cardoso \& Irmãos, 1901.

BOCAGE, Manuel Maria Barbosa du. Obras Poéticas de Bocage volume I, Sonetos. Porto: Imprensa Portugueza - Editora, 1875.

Poesias eróticas, burlescas e satíricas/ não compreendidas na edição/ que das obras d'este poeta se publicou em Lisboa,/ no anno de MDCCCLIII. Bruxelas: s. e., 1860 .

BRAGA, Teophilo. Filinto Elysio e os dissidentes da Arcadia. Porto: Livraria Chardron, 1901.

GARÇÃO, Correia. Obras completas. Texto fixado, prefácio e notas de António José Saraiva. Vol. I, poesia lírica e sátiras. Vol. II, Prosas e Teatro. Segunda edição. Lisboa: Sá da Costa, 1980.

GONÇALVES, Adelto, Bocage: o perfil perdido. Lisboa: Caminho, 2004.

GONZAGA, Tomás Antônio. Marília de Dirceu in APoesia dos Inconfidentes: Poesia completa de Cláudio Manuel da Costa, Tomás Antônio Gonzaga e Alvarenga Peixoto. Rio de Janeiro: Editora Nova Aguilar, 1996.

HORÁCIO, A Lyrica de Q. Horacio Flacco, Poeta Romano, trasladada literalmente em verso portuguez por Elpino Duriense. [António Ribeiro dos Santos] Lisboa, Na Impressam Regia. Anno 1807.

PÉCORA, Alcir, "Parnaso de Bocage, rei dos brejeiros”, in Máquina de Gêneros. São Paulo: EDUSP, 2001.

PIRES, Daniel, Da inquietude à transgressão: eis Bocage... Lisboa: Biblioteca Nacional de Portugal, 2016.

RODRIGUES, A. A. Gonçalves. A tradução em Portugal vol. 1, 1495 - 1834. Lisboa: Imprensa Nacional/ Casa da Moeda, 1992.

TEIXEIRA, Ivan. Mecenato pombalino e poesia neoclássica. São Paulo: Editora da Universidade de São Paulo: 1999.

Submetido em: 09/11/2017

Aceito em: 22/05/2018
Revista Letras, Curitiba, UfPR, n. 97, pp. 90-105, jan./jun. 2018. ISSN 2236-0999 (versão eletrônica) 